\title{
EFFECTIVENESS OF UTERINE TAMPONADE DEVICES FOR REFRACTORY POSTPARTUM HAEMORRHAGE AFTER VAGINAL BIRTH: A SYSTEMATIC REVIEW
}

\author{
Veronica Pingray $^{1}$, Mariana Widmer ${ }^{2}$, Agustín Ciapponi ${ }^{3}$, GJ Hofmeyr ${ }^{4}$, Catherine \\ Deneux-Tharaux $^{5}$, Ahmet Gulmezoglu ${ }^{6}$, Kitty Bloemenkamp ${ }^{7}$, Olufemi Oladapo ${ }^{8}$, Daniel \\ Comande $^{1}$, Ariel Bardach ${ }^{1}$, Paula Vazquez ${ }^{1}$, Gabriela Cormick ${ }^{3}$, and Fernando Althabe ${ }^{9}$ \\ ${ }^{1}$ Institute for Clinical Effectiveness and Health Policy (IECS-CONICET) \\ ${ }^{2}$ World Health organization \\ ${ }^{3}$ Institute for Clinical Effectiveness and Health Policy (IECS- CONICET) \\ ${ }^{4}$ University of Botswana \\ ${ }^{5}$ INSERM \\ ${ }^{6}$ Concept Foundation \\ ${ }^{7}$ University Medical Centre Utrecht \\ ${ }^{8}$ World Health Organization \\ ${ }^{9}$ Organisation mondiale de la Sante
}

November 27, 2020

\begin{abstract}
Objectives: to evaluate the effectiveness of uterine tamponade devices for atonic refractory postpartum haemorrhage (PPH) after vaginal birth, and the effect of including uterine tamponade devices in institutional protocols. Search strategy: databases in PubMed, EMBASE, CINAHL, LILACS and POPLINE. Study selection: randomised and non-randomised comparative studies. Outcomes: composite outcome including surgical interventions (artery ligations, uterine compressive sutures or hysterectomy) or maternal death, and hysterectomy. Results: all four included studies were at high risk of bias. The certainty of evidence rated as very low to low. One randomised study measured the effect of the the condom-catheter balloon compared to standard care and found unclear results for the composite outcome (RR 2.33, 95\%CI 0.76-7.14) and hysterectomy (RR 4.14, 95\%CI 0.48-35.93). Three comparative studies assessed the effect of including UBTs in institutional protocols. A stepped-wedge study suggested an increase in the composite outcome (RR 4.08, 95\% CI 1.07-15.58), and unclear results for hysterectomy (RR 4.38, 95\% CI 0.47-41.09) with the use of the condom-catheter or surgical glove balloon. One non-randomised study showed unclear effects on the composite outcome (RR 0.33, 95\%CI 0.11-1.03) and hysterectomy (RR 0.49, 95\%CI 0.04-5.38) after the inclusion of Bakri balloon. The second non-randomized study found unclear effects on the composite outcome (RR 0.95, 95\% CI 0.32-2.81) and hysterectomy (RR 1.84, 95\% CI 0.44-7.69) after the inclusion of Ebb or Bakri balloon. Conclusions: the effect of uterine tamponade devices for the management of atonic refractory PPH after vaginal delivery is unclear, as is the role of the type of device and the setting.
\end{abstract}

\section{Hosted file}

Main text v3.pdf available at https://authorea.com/users/333500/articles/495707effectiveness-of-uterine-tamponade-devices-for-refractory-postpartum-haemorrhage-aftervaginal-birth-a-systematic-review 


\section{Hosted file}

Figure 1.pdf available at https://authorea.com/users/333500/articles/495707-effectivenessof-uterine-tamponade-devices-for-refractory-postpartum-haemorrhage-after-vaginal-birtha-systematic-review 